\title{
Práticas de Criação de Aplicativos Móveis como Estratégia para o Empoderamento Feminino
}

\author{
Jaline Gonçalves Mombach ${ }^{1}$, Cristiane Jorge de Lima Bonfim ${ }^{1}$, \\ Alane Beatriz da Nóbrega Martins ${ }^{1}$, Janara Kalline Leal Lopes de Sousa ${ }^{2}$
}

${ }^{1}$ Instituto de Educação, Ciência e Tecnologia de Brasília - Campus Brasília

Setor de Grandes Áreas Norte 610 - Asa Norte - 70830-450 - Brasília - DF - Brasil

${ }^{2}$ Faculdade de Comunicação - Universidade de Brasília (UnB)

Campus Darcy Ribeiro - ICC Norte Asa Norte - 70 910-900 - Brasília - DF - Brasil

\{jaline.mombach, cristiane.bonfim\}eifb.edu.br

\{janara.sousa, alane.nm\}@gmail.com

\begin{abstract}
Research has shown that female participation in the technological area is smaller when compared to male representation. Also, initiatives aimed at empowering girls and women are encouraged worldwide.This article presents an experience report for teaching mobile application programming to girls. This activity is part of the project "Escola de App"that discusses online gender violence in Brazilian public schools. The methodology involved three meetings with design, programming, and evaluation tasks. After, the girls answered a questionnaire, and the answers allow us to discuss quantitatively and qualitatively the advantages and the effectiveness of such a practice.
\end{abstract}

Resumo. Pesquisas mostram que a participação feminina na área tecnológica é menor quando comparada à representação masculina. Além disso, iniciativas voltadas ao empoderamento de meninas e mulheres são incentivadas em todo o mundo. Este artigo apresenta um relatório de experiência para o ensino de programação de aplicativos móveis para meninas. Esta atividade faz parte do projeto "Escola de App", que discute a violência de gênero on-line nas escolas públicas brasileiras. A metodologia envolveu três reuniões com tarefas de design, programação e avaliação. Depois, as meninas responderam a um questionário, e as respostas nos permitem discutir quantitativa e qualitativamente as vantagens e a efetividade de tal prática.

\section{Introdução}

A Organização das Nações Unidas (ONU) estabeleceu um plano de ações para o desenvolvimento sustentável que visa até 2030 realizar medidas transformadoras no mundo ${ }^{1}$. Composto por dezessete objetivos, esse documento visa que todos os países implementem estratégias para acabar com a fome, proteger o planeta, promover a paz, entre outros.

De forma mais específica, o quinto objetivo trata a igualdade de gênero e uma das nove metas desse conjunto é "aumentar o uso de tecnologias de base, em particular as

\footnotetext{
${ }^{1}$ Disponível em http://nacoesunidas.org/wp-content/uploads/2015/10/ agenda2030-pt-br.pdf
} 
VII Congresso Brasileiro de Informática na Educação (CBIE 2018)

Anais do XXIV Workshop de Informática na Escola (WIE 2018)

tecnologias de informação e comunicação, para promover o empoderamento das mulheres" [ONU Brasil 2015]. O termo empoderamento compreende muitos conceitos, porém de maneira geral pode ser entendido como a "ampliação da liberdade de escolher e agir, ou seja, o aumento da autoridade e do poder dos indivíduos sobre os recursos e decisões que afetam suas próprias vidas" [ONU Mulheres 2017].

A baixa representatividade feminina no mercado de TI e também no meio acadêmico, tem sido objeto de estudo em diversos países. No Brasil, uma análise da Sociedade Brasileira de Computação (SBC) sobre o perfil do ensino superior na área de Computação, mostra que de fato, a presença de mulheres como estudantes na área é expressivamente menor que a dos homens, sendo apenas aproximadamente $14,65 \%$ do total de matrículas [Nunes 2015].

No contexto apresentado, quando se trata especificamente de tecnologia, o empoderamento feminino alinha-se à necessidade das mulheres terem seus próprios conhecimentos reconhecidos no campo da Tecnologia da Informação (TI) e/ou serem promovidos espaços e ações para que esse público tenha maior compreensão sobre a TI, saiba resolver problemas e adquira as demais competências comuns à área, a fim de ampliar a participação ativa das mulheres nesse meio.

Diante desse cenário, este artigo relata a experiência obtida em práticas para criação de aplicativos por meninas do ensino médio. A ação está vinculada a um projeto mais amplo, que visa compreender a violência on-line de gênero e propor esse debate nas escolas públicas. O trabalho está organizado como segue. Na Seção 2, apresentase iniciativas similares a essa ação, já conhecidas no âmbito da Comissão Especial de Informática na Educação (CEIE). Na Seção 3, explica-se o projeto Escola de App, contextualizando a etapa relatada neste artigo, bem como as ferramentas utilizadas. Na Seção 4 , relata-se os encontros e na Seção 5, descreve-se os resultados preliminares. Por fim, a Seção 6 discorre as considerações finais.

\section{Trabalhos Relacionados}

Há exemplos de trabalhos no país que se propõem a utilizar a programação em blocos como ferramenta de incentivo ao ensino e à aprendizagem de Exatas, focando a participação de meninas na área de Ciência da Computação.

O Scratch foi usado em um projeto de extensão para aumentar o interesse de meninas do ensino médio na área, por meio de sua aplicação no ensino de química, física e matemática. Os resultados indicam a criação de animações e documentos interativos para estudantes do Ensino Médio, que foram baseados em planos pedagógicos previamente elaborados [Gomes et al. 2014].

Um exemplo de projeto, que não apenas apresenta atividades pedagógicas que se utilizam do ensino de Computação na educação básica, mas agrega reflexões sobre as diferenças entre a participação de homens e de mulheres nos espaços de Ciência e Tecnologia, é a experiência desenvolvida no projeto 'Desafio de Programação para Meninas". O projeto objetivou encorajar meninas do Ensino Médio a se interessarem por carreiras na área de Computação. A partir de um conjunto de atividades empregadas (palestras, oficinas, cursos, ateliers, competição), nas quais foram aplicados o conceito e a prática de programação, visou-se a produção de aplicativos para a plataforma Android, com o intuito 
VII Congresso Brasileiro de Informática na Educação (CBIE 2018)

Anais do XXIV Workshop de Informática na Escola (WIE 2018)

de se resolver um problema social, a partir do uso da ferramenta APP Inventor. A etapa final resultou num desafio de programação, na qual houve a criação de alguns aplicativos [Santos et al. 2017].

Além dos projetos mencionados, outros podem ser citados no âmbito da Comissão Especial de Informática na Educação [Moreira et al. 2016, Mattos et al. 2016, Pinheiro et al. 2017]. Porém, nossa proposta se diferencia das demais devido ao contexto empregado, ou seja, não é uma atividade isolada para ensinar programação à meninas. Conforme descrito na próxima Seção, a atividade contempla grupos focais com pessoas especialistas em violência de gênero e somente após essa reflexão é que as meninas são convidadas a pensarem em aplicativos com essa temática.

\section{Método Aplicado}

O projeto "Escola de app: enfrentando a violência on line contra meninas"2, é um projeto de pesquisa desenvolvido no âmbito do grupo de pesquisa Internet e Direitos Humanos, que integra o Laboratório de Políticas de Comunicação (Lapcom) da Faculdade de Comunicação da Universidade de Brasília (UnB), em parceria com o Laboratório de Tecnologias Educacionais do Instituto Federal de Brasília - Campus Brasília. A pesquisa tem o objetivo de compreender a violência on-line de gênero, apontando suas características, sua recorrência, sua tipologia, bem como as consequências para as vítimas, propondo ações de enfrentamento interinstitucional no âmbito das escolas públicas de ensino médio e servindo de subsídio para a criação da Rede Nacional de Proteção às Mulheres e Meninas na Internet, conforme apresentado na Figura 1 .

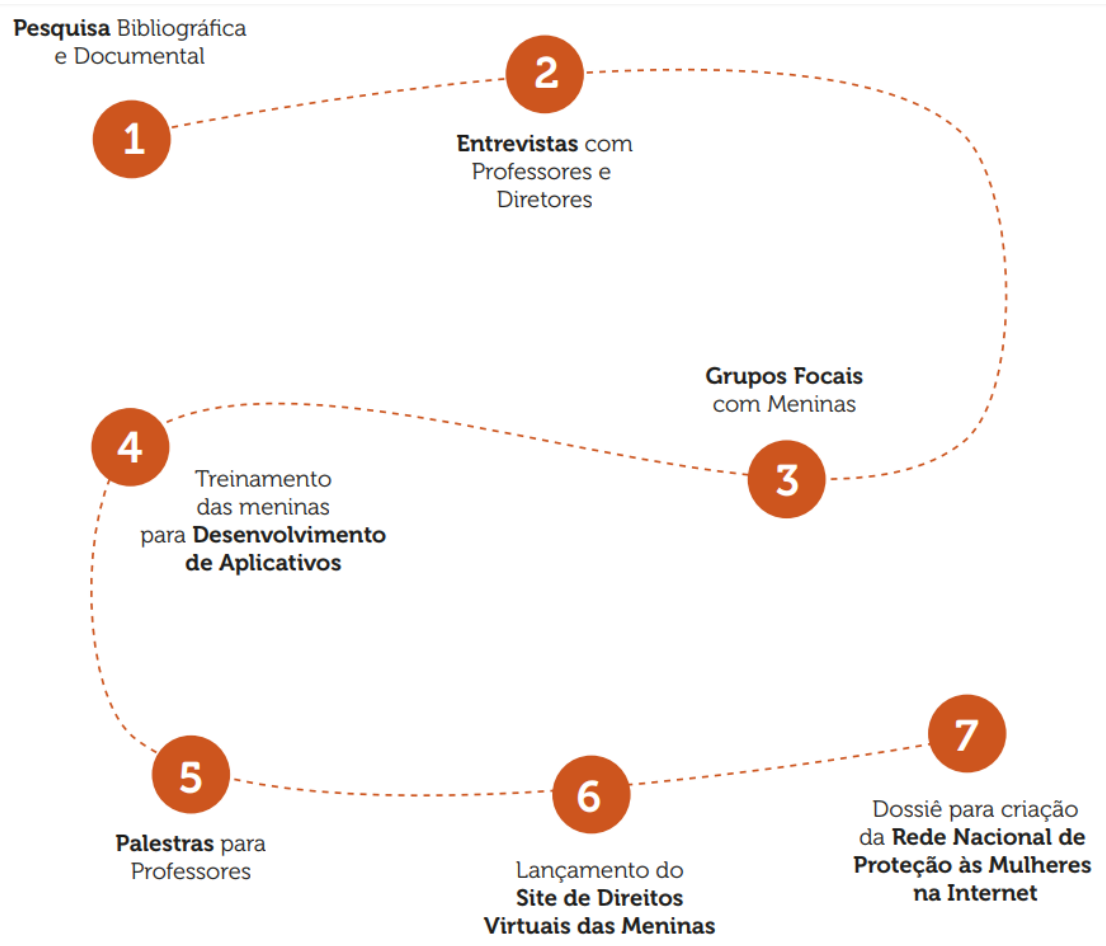

Figura 1. Etapas do Projeto

\footnotetext{
${ }^{2}$ Projeto Escola de app. Disponível em: ¡https://www.internetedireitoshumanos.com.br/publicacoes $\underset{j}{ }$. Acesso em: 12 jun 2018.
} 
VII Congresso Brasileiro de Informática na Educação (CBIE 2018)

Anais do XXIV Workshop de Informática na Escola (WIE 2018)

O projeto é organizado em sete etapas previstas para realização de pesquisa bibliográfica e documental, entrevistas com diretores e professores, grupos focais com meninas, treinamento das meninas para desenvolvimento de aplicativos, palestras para professores, culminando na criação de um dossiê que visa o desenvolvimento de uma rede nacional de proteção às mulheres na internet. Nesse contexto, este artigo limita-se ao relato da experiência obtida na etapa quatro do projeto, ou seja, na realização do treinamento das meninas para criação e desenvolvimento de aplicativos móveis.

\subsection{Recursos Utilizados para Criação dos Aplicativos}

Em um estudo sobre iniciativas que atraem meninas para a Ciência da Computação, os autores mencionam que é importante escolher a ferramenta conforme a faixa etária do grupo, sua facilidade de uso, objetivo da proposta e consequentemente, a indicação segundo o nível de conhecimento. Logo, descrevem que as ferramentas mais utilizadas nessas atividades são Alice, Lego Mindstorm, Scratche App Inventor ${ }^{3}$ [Moreira et al. 2016].

As plataformas mencionadas possuem em comum a característica de maior apelo visual, ou seja, a programação é facilitada com uso de blocos. Em análise, percebeu-se que a ferramenta mais apropriada para adoção nas práticas seria o App Inventor, visto que entre as gratuitas, a Alice necessita de instalação no sistema operacional e ocupa aproximadamente $1,5 \mathrm{~Gb}$ em disco e a equipe considerou o Scratch um ambiente mais infantilizado quando comparado à interface gráfica do App Inventor.

Além do App Inventor, aplicações do Google Drive (Google Apresentações e Google Desenhos) foram utilizados para criação das telas e tutoriais e também bancos com imagens vetoriais gratuitas, como FlatIcon ${ }^{4}$, FreePik ${ }^{5}$ e Icons $8^{6}$. Na próxima Seção relatase como foram usadas essas ferramentas, conforme a programação prevista nos encontros.

\section{Relato de Experiência}

A etapa de criação dos aplicativos foi desenvolvida em três encontros de quatro horas, para cada grupo. A agenda que foi prevista para os encontros é apresentada na Figura 2, sendo o foco principal em design, programação e validação, respectivamente.

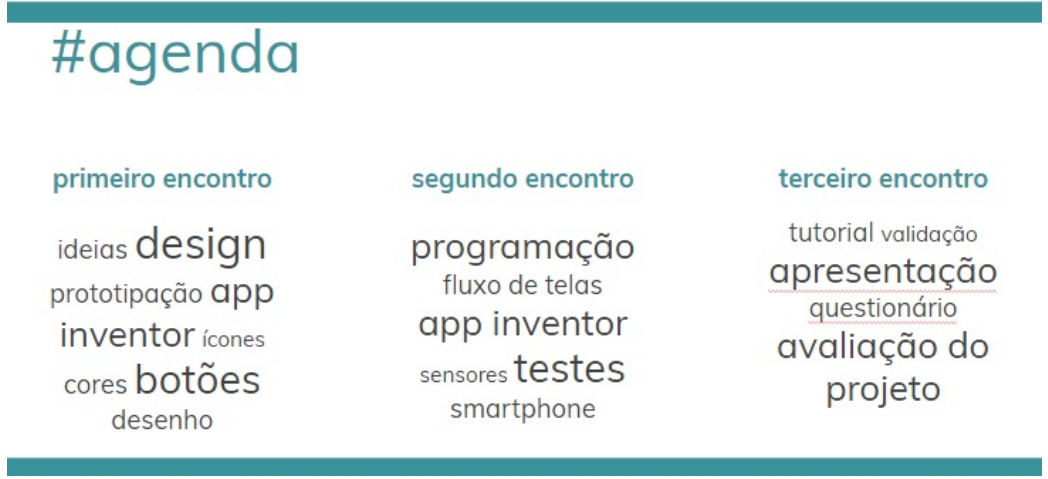

Figura 2. Agenda dos Encontros

\footnotetext{
${ }^{3}$ Disponível em http://appinventor.mit.edu/explore/

${ }^{4}$ Disponível em https : / / www. flaticon.com/

${ }^{5}$ Disponível em https://br.freepik.com/

${ }^{6}$ Disponível em https: // icons 8 .com.br/
} 
VII Congresso Brasileiro de Informática na Educação (CBIE 2018)

Anais do XXIV Workshop de Informática na Escola (WIE 2018)

As participantes da etapa compuseram dois grupos, sendo um no turno da manhã e outro no turno da tarde, com previsão de dez participantes em cada grupo. As meninas tinham entre quatorze e dezenove anos de idade, sendo que o grupo da manhã e da tarde cursa o $1^{\circ}$ e $2^{\circ}$ ano do ensino médio, respectivamente. A equipe executora foi composta por duas professoras da área da Computação e uma aluna do Curso Técnico de Desenvolvimento de Sistemas.

A agenda proposta objetiva criar espaços para o trabalho em grupo e a construção colaborativa, fomentando ideias de design prototipação, além da aproximação e uso básico da ferramenta App Inventor do MIT utilizada para desenvolvimento dos aplicativos. Ao final do terceiro encontro, além da apresentação dos apps criados e publicados na galeria do ambiente, foi feita uma avaliação da etapa.

\subsection{Primeiro Encontro}

O primeiro encontro teve como proposta apresentar os conceitos de aplicativos e seu ciclo de desenvolvimento, desde a ideia inicial, passando pela codificação, testes, compartilhamento e a avaliação dos usuários. Neste estágio do encontro e considerando o público-alvo recorte do projeto, entendeu-se necessário tratar a dimensão do empoderamento adolescente dentro da lógica da capacidade de criação e produção de aplicativos, e para esta sensibilização, foram apresentados casos de destaque na mídia sobre aplicativos de sucesso criados por adolescentes.

Na sequência, iniciou-se a abordagem sobre os conceitos de programação, partindo do ponto inicial do algoritmo, software e programas, para que neste percurso fosse construída trilha lógica conceitual do ponto de vista da programação pela qual perpassa a criação de um aplicativo com linguagem compatível com a do público-alvo.

Feita a introdução, a trilha segue na busca de trazê-las ao envolvimento do tema principal que é o desenvolvimento de aplicativos, e este momento propõe conhecer os aplicativos utilizados pelo grupo em seu quotidiano com foco nas mulheres, considerando o recorte do projeto Escola de App é o enfrentamento à violência on-line contra meninas. Este foi um momento bastante interessante, com forte envolvimento das participantes. Percebeu-se nas atividades anteriores a essa etapa que a visão de aplicativos das meninas limitava-se apenas às redes sociais, por isso foram apresentados outros cinco aplicativos, conforme Tabela 1, para que pudessem servir de referências à criação dos protótipos dos aplicativos.

Para uma aproximação sobre as possibilidades de implementação de funcionalidades em aplicativos foi apresentado também um aplicativo com implementação de sensores como balançar o telefone para mudar de tela. Após, cada dupla teve que discutir a ideia do seu app (brainstorming), elaborar mockups das telas em papel e elaborar um cartaz com o fluxo de telas, simulando um diagrama de atividades.

Na sequência, apresentou-se as funcionalidades do modo Design do App Inventor. Logo, as duplas passaram a construir as telas do aplicativo com uso de imagens gratuitas, cujas bases já foram citadas na Seção 3.1. Além disso, foram lhes apresentados códigos de cores em hexadecimal, para que pudessem ter maiores opções. Ao final deste primeiro encontro a proposta era que as principais telas do protótipo fossem criadas para a implementação dos blocos de navegação entre as telas e demais funcionalidades do aplicativo no segundo encontro que trataremos na sequência. 
VII Congresso Brasileiro de Informática na Educação (CBIE 2018)

Anais do XXIV Workshop de Informática na Escola (WIE 2018)

Tabela 1. Exemplos de aplicativos para proteção da mulher

\begin{tabular}{|l|l|l|}
\hline Nome do App & Descrição & Link \\
\hline Juntas & $\begin{array}{l}\text { conecta mulheres a uma rede de proteção } \\
\text { que poderá ser acionada em situações de } \\
\text { perigo }\end{array}$ & https://juntas.geledes.org.br/ \\
\hline Protege M & $\begin{array}{l}\text { criado por estudantes da UFMG, o app pos- } \\
\text { sui um guia, que contém projetos de leis e } \\
\text { emendas que interferem ou modificam os } \\
\text { direitos da mulher. }\end{array}$ & http://bit.do/protegem \\
\hline $\begin{array}{l}\text { Frases de Empode- } \\
\text { ramento Feminino }\end{array}$ & $\begin{array}{l}\text { coletânea de frases de grandes ícones da } \\
\text { luta pela igualdade de gênero }\end{array}$ & $\mathrm{http} / / / \mathrm{bit} . d o / f r a s e s f$ \\
\hline Apoio Vítima & $\begin{array}{l}\text { ajuda a reconhecer se a pessoa está vivendo } \\
\text { situação de violência doméstica }\end{array}$ & $\mathrm{http}: / / \mathrm{bit} . d o /$ apoiov \\
\hline $\begin{array}{l}\text { Bem Querer Mu- } \\
\text { lher }\end{array}$ & $\begin{array}{l}\text { facilita o atendimento a vítima de violência } \\
\text { doméstica e de gênero }\end{array}$ & $\mathrm{http} / / / \mathrm{bit} . d o /$ bemquerer \\
\hline
\end{tabular}

\subsection{Segundo e Terceiro Encontro}

O segundo encontro teve como objetivo a finalização de eventuais telas que ficaram pendentes no encontro anterior e principalmente programar os blocos. Antes de começar a executar essa segunda etapa dos aplicativos, foram introduzidos os significados das diferentes funções dos blocos, conforme explicitado no item 3.3, como: a) controle; b) lógica; c) matemática; d) texto; e) listas; f) cores; g) variáveis; h) procedimentos. Também foi demonstrado o uso de sensores, como: acelerômetro, código de barras, temporizador, giroscópio, localização, nearfield, orientação, pedômetro e proximidade.

Após esta etapa introdutória, as estudantes puderam iniciar a construção dos blocos em seus aplicativos, a partir do planejamento disposto no mockup desenhado no primeiro encontro. O passo seguinte foi conhecer os conceitos de $Q R$ Code e de compilação, para, então, gerarem um código para o apk, baixando o aplicativo diretamente nos smartphones. A instalação foi necessária para que os testes pudessem ser realizados.

O App Inventor dispõe de seu próprio emulador ou visualizador em tempo real no dispositivo móvel, a partir do uso de seu aplicativo (MIT AI2 Companion). Entretanto, devido a limitações técnicas, optou-se pela instalação dos aplicativos, visando facilitar o manuseio diretamente do aparelho.

O terceiro e último encontro, foi para finalização da programação e também construção da "documentação". Depois que a construção dos aplicativos foi finalizada, as estudantes foram orientadas a produzirem um tutorial que explicasse o objetivo do aplicativo e ensinasse a utilizá-lo. Com a conclusão dessa última fase, foi apresentada a opção de publicação dos projetos na galeria do App Inventor. As meninas desenvolveram nove aplicativos, os quais contemplaram temáticas como violência contra a mulher ou contra minorias, empoderamento feminino, LGBT ou racial, espaços para conversa e estímulo à participação feminina no futebol. A Figura 3 exibe a tela inicial de todos os aplicativos criados. Para avaliação, as participantes responderam um questionário, detalhado na próxima Seção. 
VII Congresso Brasileiro de Informática na Educação (CBIE 2018)

Anais do XXIV Workshop de Informática na Escola (WIE 2018)

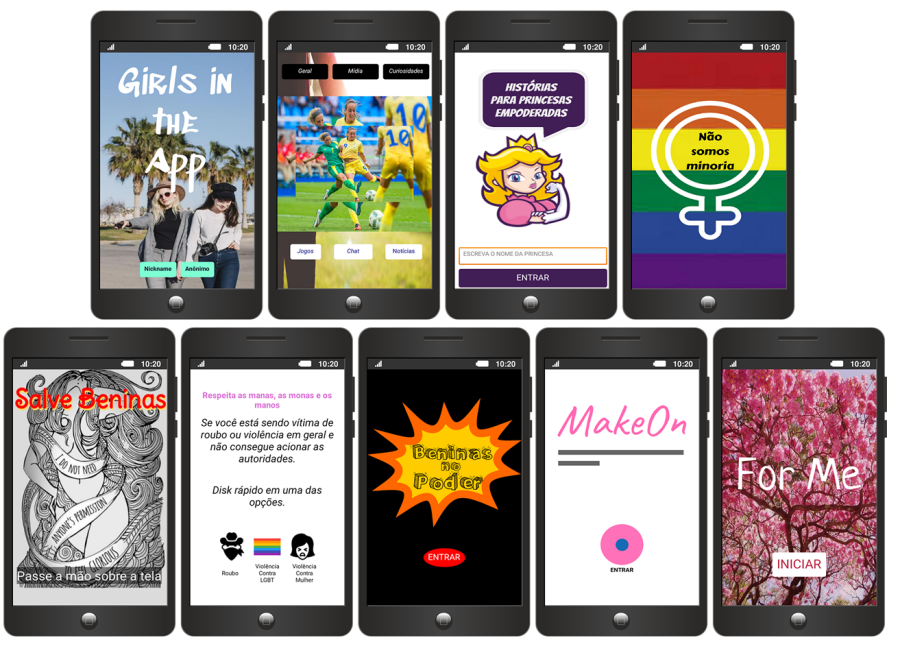

Figura 3. Apps desenvolvidos ao término da etapa

\section{Resultados Preliminares}

Após finalização dos encontros, a equipe encaminhou por e-mail e no grupo on-line o convite para preenchimento de um questionário on-line avaliativo. Por se tratar de um grupo de adolescentes, o questionário foi preparado com linguagem mais adequada ao público, adotando figuras e expressões informais, como exibem as telas apresentadas na Figura 4.
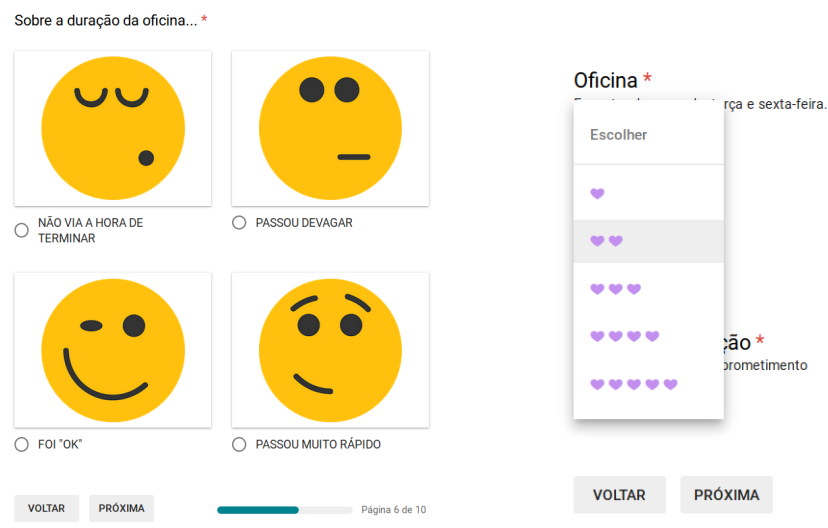

Figura 4. Exemplos de questões apresentadas às meninas, com uso de emoticons, classificação e linguagem adaptada à faixa-etária

Das dezenove meninas participantes, dezoito responderam o questionário que ficou disponível por 7 dias, após finalização dos encontros. A primeira pergunta, "O que te motivou a fazer o app?" teve como maioria das respostas a possibilidade de ajudar outras mulheres, conforme apresentado na Figura 5.

As próximas questões tiveram como objetivo identificar se o interesse pela área tecnológica havia mudado após a experiência e os gráficos são apresentados na Figura 6. Sobre antes do projeto, três participantes indicaram que o interesse era nenhum $(16,7 \%)$, duas que era pequeno $(11,1 \%)$, nove que era moderado $(50 \%)$ e apenas quatro indicavam interesse muito grande pela área $(22,2 \%)$. 
VII Congresso Brasileiro de Informática na Educação (CBIE 2018)

Anais do XXIV Workshop de Informática na Escola (WIE 2018)

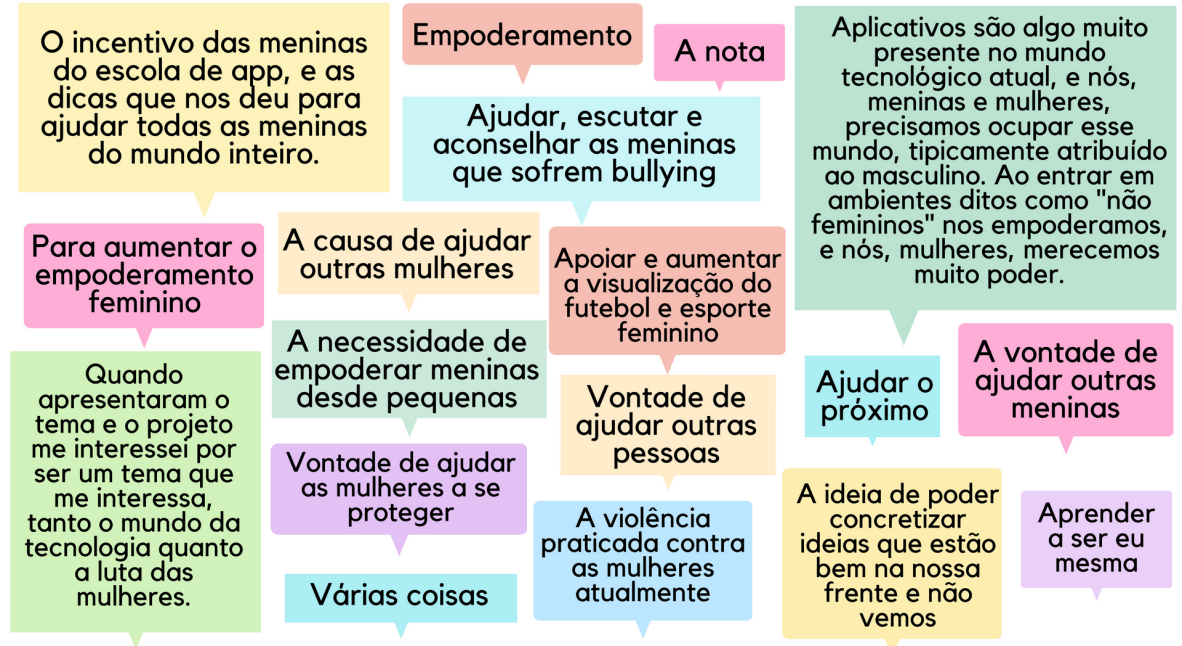

Figura 5. Respostas para a pergunta "O que te motivou a fazer o app?"

Porém, após as atividades, das meninas que responderam "nenhum", apenas uma continuou com essa manifestação, a outras duas mudaram para interesse "moderado". As duas meninas que marcaram interesse "pequeno", mudaram para "muito grande". Das meninas que já tinham interesse moderado, três mantiveram essa opinião e as demais mudaram para "muito grande". As participantes que já manifestavam interesse muito grande na área, não modificaram a marcação.

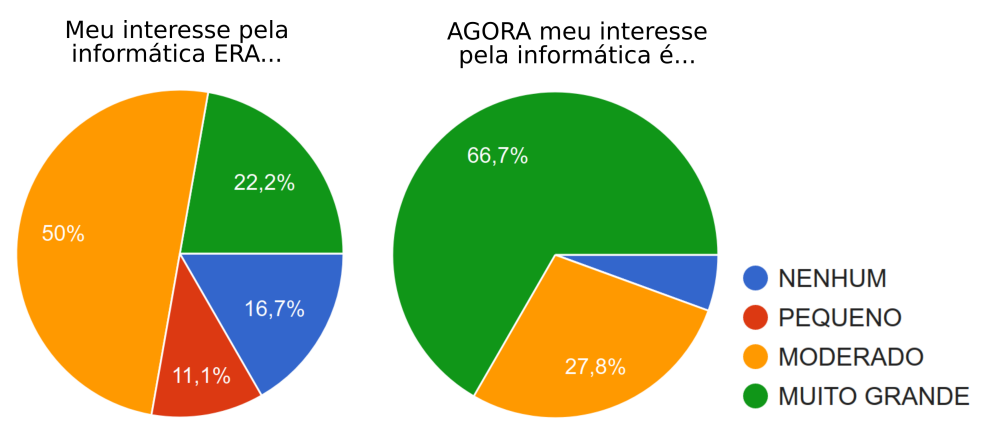

Figura 6. Perguntas "Meu interesse pela informática ERA..." e "AGORA meu interesse pela informática é...”. Dezessete meninas indicaram interesse moderado a muito grande pela área após a participação no projeto.

Na sequência, questionou-se a opinião delas quanto ao nível de dificuldade para criar um aplicativo no App Inventor e uma menina considerou muito difícil (5,6\%), sete marcaram que é difícil $(38,9 \%)$, outras sete indicaram que é fácil $(38,9 \%)$ e três meninas que é muito fácil(16,7\%). Pelas observações da equipe, a maior dificuldade foi na parte dos blocos, devido exigência de habilidades lógico-matemáticas para acrescentar as funções, mesmo assim percebe-se que aproximadamente $55 \%$ das meninas consideram fácil ou muito fácil criar aplicativos na plataforma indicada.

Outro fator que indica dificuldade foi o tempo de duração da oficina, dezesseis meninas informaram que "passou muito rápido" $(88,9 \%)$, uma achou "muito devagar" e outra considerou "ok" o tempo, ou seja, tempo razoável. Além disso, na pergunta "O que poderia ter sido diferente nessa etapa?", treze meninas mencionaram maior tempo ou 
VII Congresso Brasileiro de Informática na Educação (CBIE 2018)

Anais do XXIV Workshop de Informática na Escola (WIE 2018)

mais aulas $(72 \%)$, enquanto três escreveram "nada", uma indicou "tudo perfeito" e outra "As pessoas (alunas)".

Quanto à oficina de maneira geral, a equipe e a participação individual de cada uma, elas avaliaram em formato de escala, entre 1 e 5 corações. Os resultados são apresentados na Figura 7 e percebe-se que a maioria recebeu avaliação máxima.
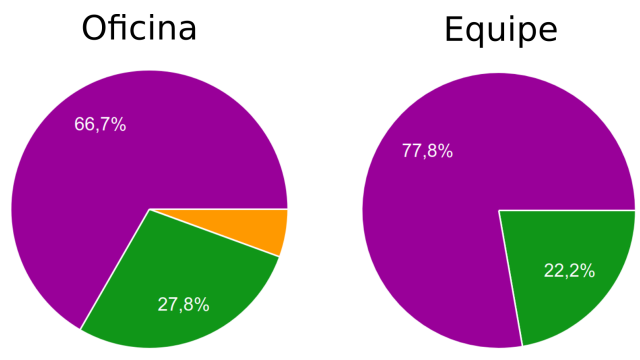

Minha Participação

Figura 7. Avaliação da oficina, equipe e participação individual.

Perguntou-se o que foi mais legal na oficina e a maioria indicou a possibilidade de criar seu próprio app, a finalização do aplicativo, ou seja, vê-lo funcionando no celular. Por fim, questionou-se se a relação com a tecnologia havia mudado e o porquê. A Figura 8 exibe o relato das meninas e percebe-se que apenas uma menina indicou que não houve mudança para ela.

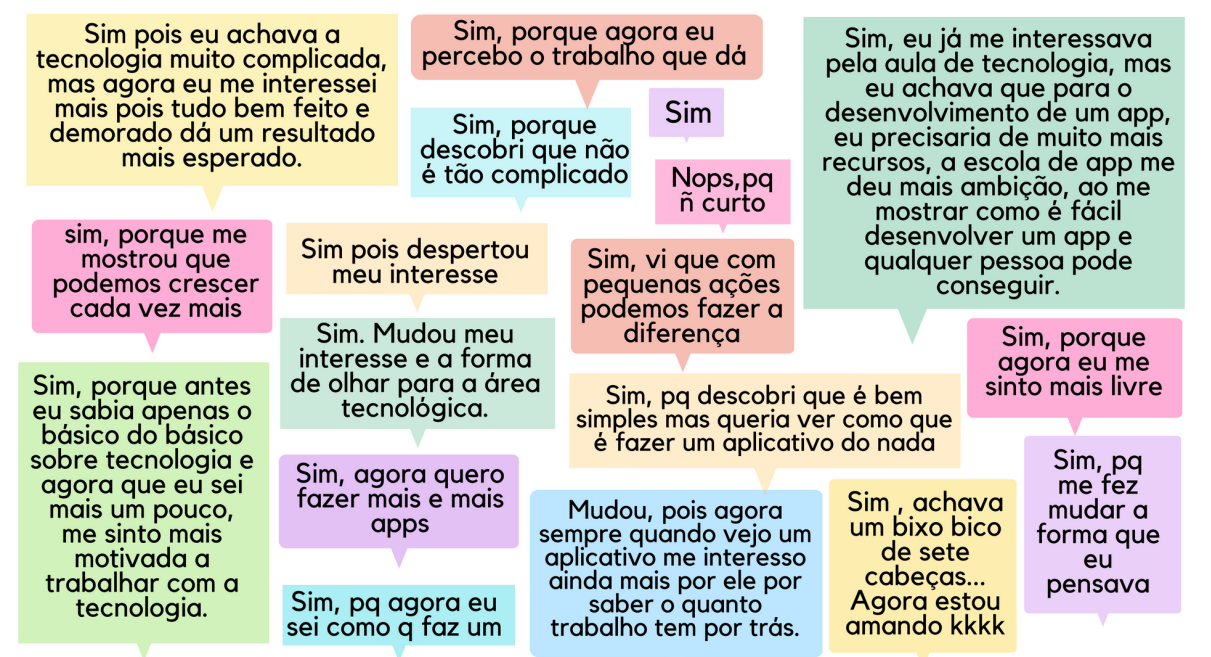

\section{Figura 8. Respostas para a pergunta "O desenvolvimento de um app mudou sua relação com a tecnologia? Por quê?".}

De maneira geral a experiência foi avaliada como enriquecedora pela equipe executora e as considerações finais são discorridas na próxima Seção.

\section{Considerações Finais}

Este artigo relatou a experiência adquirida na realização do treinamento de meninas para desenvolvimento de aplicativos móveis na plataforma App Inventor. Ao total, as meninas desenvolveram nove aplicativos que contemplaram temáticas discutidas na etapa conceitual do projeto, como violência contra a mulher ou contra minorias, empoderamento 
VII Congresso Brasileiro de Informática na Educação (CBIE 2018)

Anais do XXIV Workshop de Informática na Escola (WIE 2018)

feminino, LGBT ou racial, espaços para conversa e estímulo à participação feminina no futebol.

$\mathrm{Na}$ avaliação da etapa pelas meninas, o interesse pela área de Informática ficou três vezes maior após a criação do app e elas indicaram que o que mais gostaram foi desenvolver seu próprio app e vê-lo funcionando em seu celular. Os resultados apresentados neste trabalho ainda são considerados preliminares pois cabe salientar que é previsto aplicação em outras três escolas, que trarão novos elementos para análise mais ampla, elucidativa e conclusiva.

Por fim, recomenda-se que ações similares sejam desenvolvidas pois a aproximação de meninas com a tecnologia pode ser uma ação para o empoderamento feminino e inclusão de mulheres na Computação.

\section{Referências}

Gomes, W. F., Louzada, C. S., Nunes, M. A. S. N., Salgueiro, E. M., and Andrade, B. T. (2014). Incentivando meninas do ensino médio à área de ciência da computação usando o scratch como ferramenta. In Anais do Workshop de Informática na Escola, volume 20, page 223 .

Mattos, F., Ferreira, V., and Anacleto, J. (2016). O ensino de programação com scratch e seu impacto na opção profissional para meninas. In Brazilian Symposium on Computers in Education (Simpósio Brasileiro de Informática na Educação-SBIE), volume 27, page 300 .

Moreira, J., Mattos, G., Barreto, L., Cavaco, I., and Moreira, R. (2016). Atraindo meninas para a ciência da computação: Métodos e ferramentas. In Anais dos Workshops do Congresso Brasileiro de Informática na Educação, volume 5, page 1255.

Nunes, D. (2015). Educação superior em computação, estatísticas 2015. Sociedade Brasileira de Computação-SBC. Disponível em:; http://www. sbc. org. br/documentos-dasbc/summary/133-estatisticas/1074-educacaosuperior-em-Computação-estatisticas2015: Acesso em, 6.

ONU Brasil (2015). Transformando nosso mundo: A agenda 2030 para o desenvolvimento sustentável. https://nacoesunidas.org/pos2015/agenda2030/. Online; Acesso em 12 jun. 2018.

ONU Mulheres (2017). Princípios de empoderamento das mulheres. http://www.onumulheres.org.br. Online; Acesso em 12 jun. 2018.

Pinheiro, A., Franco, J., and Leite, J. (2017). Desenvolvimento do pensamento computacional e discussões sobre representação feminina na computação: um estudo de caso. In Anais dos Workshops do Congresso Brasileiro de Informática na Educação, volume 6, page 1111 .

Santos, C. P., Silva, D., Silveira, M., and Ferreira, G. (2017). Desafio de programação para meninas do ensino médio: Um relato de experiência. In Anais do Workshop de Informática na Escola, volume 23, page 137. 